\title{
Bayesian analysis of time-varying interactions between stock returns and foreign equity flows
}

\author{
Boubekeur Baba ${ }^{1 *}$ (D) and Güven Sevil ${ }^{2}$
}

\author{
*Correspondence: \\ bb359@anadolu.edu.tr \\ ${ }^{1}$ Graduate School of Social \\ Sciences, Anadolu University, \\ Eskişehir, Tepebaşı 26470, \\ Turkey \\ Full list of author information \\ is available at the end of the \\ article
}

\begin{abstract}
This study discusses the trading behavior of foreign investors with respect to economic uncertainty in the South Korean stock market from a time-varying perspective. We employ a news-based measure of economic uncertainty along with the model of time-varying parameter vector autoregression with stochastic volatility. The empirical analysis reveals several new findings about foreign investors' trading behaviors. First, we find evidence that positive feedback trading often appears during periods of high economic uncertainty, whereas negative feedback trading is exclusively observable during periods of low economic uncertainty. Second, the foreign investors' feedback trading appears mostly to be well-timed and often leads the time-varying economic uncertainty except in periods of global crises. Third, lagged negative (positive) response of net flows to economic uncertainty is found to be coupled with lagged positive (negative) feedback trading. Fourth, the study documents an asymmetric response of foreign investors with regard to negative and positive shocks of economic uncertainty. Specifically, we find that they instantly turn to positive feedback trading after a negative contemporaneous response of net flows to shocks of economic uncertainty. In contrast, they move slowly toward negative feedback trading after a positive response of net flows to uncertainty shocks.
\end{abstract}

Keywords: Stock returns, Net foreign equity flows, Time-varying parameter VAR, Feedback trading, Forecast ability, Economic policy uncertainty

JEL Classification: G11, G14, G15

\section{Introduction}

The liberalization of financial markets in emerging economies sparked significant international capital movements, most of which have been short-term portfolio investments and instruments. In this regard, foreign investors have often been perceived as highly influencing in terms of stock prices in these markets and, therefore, their trading behaviors were of interest to policymakers and many academic researchers. The studies in this regard frequently labeled foreign investors as trend chasers who often follow positive feedback trading strategies, which may potentially destabilize emerging stock markets. ${ }^{1}$

\footnotetext{
${ }^{1}$ Liquidity erosion is one of the side effects of foreign capital that arises in the events of sudden reverse of foreign flows; for example, see Liew et al. (2018).
} party material in this article are included in the article's Creative Commons licence, unless indicated otherwise in a credit line to the material. If material is not included in the article's Creative Commons licence and your intended use is not permitted by statutory regulation or exceeds the permitted use, you will need to obtain permission directly from the copyright holder. To view a copy of this licence, visit http:// creativecommons.org/licenses/by/4.0/. 
Despite the fact that the trend-chasing behaviors of foreign investors are consistently supported by empirical evidence from studies at multiple-country level (e.g., Froot et al. 2001; Griffin et al. 2002; Richards 2005; Chai-Anant and Ho 2008), and at a single-country level such as Karolyi (2002) on Japan, Chai-Anant (2003) on Thailand, Tayde and Rao (2011) on India, and Bae et al. (2011) on South Korea, the findings from some recent studies have pointed to a negative relationship, which is often hypothesized as "portfolio rebalancing" behavior (e.g., Hau and Rey 2004; Ülkü and Ikizlerli 2012; Ülkü and Karpova 2014; Ülkü 2015). Furthermore, the literature on international finance has provided several explanations about foreigners' positive feedback trading. Home-bias models describe foreign investors as uninformed traders and attribute their positive feedback trading to lack of information about the local market (Brennan and Cao 1997; Griffin et al. 2004). However, some studies contrasted this finding and provided evidence on foreign investors' outperformance of their domestic counterparts (e.g., Grinblatt and Keloharju 2000; Froot and Ramadorai 2008). In light of these results, Albuquerque et al's (2009) global private information model argues that positive feedback trading is not a symptom of inferior knowledge at a domestic level, but it is actually due to the foreign investors' superior information at a global level.

Although there is a considerable body of research on the relationship between foreign equity flows and stock returns, several aspects of this relationship require further investigations. As highlighted by another stream of research, emerging stock markets are characterized by high volatility and more frequent price changes compared to developed markets (e.g., see Bekaert and Harvey 1997; De Santis and Imrohoroglu 1997; Schaller and Van Norden 1997; Bekaert et al. 1998; Kawakatsu and Morey 2014; Harvey et al. 2000). Besides being highly volatile, other studies have confirmed that the volatility of returns in emerging stock markets is time-variant. Ahmed and Sehgal (2015) investigate the volatility of stock returns in seven emerging markets using the Markov switching model. The study revealed that volatility switches between two regimes in each of the studied markets. Similarly, Maharaj et al. (2011) observe that volatility of stock returns is time scale-dependent in all the countries in their sample of emerging and developed markets.

In a similar fashion, the net foreign portfolio flows can be highly inconstant and may deteriorate in a short period. Pagliari and Hannan (2017) conducted a study on 65 countries including emerging markets, and found the portfolio flows to be following different trends over time. According to the authors, the volatility of overall portfolio flows is lower at certain periods. More precisely, they find that the volatility of equity flows is following a slight upward trend until the global financial crisis and a downward trend thereafter. In addition, the net portfolio flows have been frequently changing in size over time; it has occasionally surged then suddenly reversed with dramatic falls over the past 2 decades. These types of changes are capable of generating regime shifts and structural breaks. Consequently, the relationship between foreign equity flows and stock returns is likely to be time-variant and non-linear. Based on this perspective, the current study analyzes the dynamic interactions between the net foreign equity flows and stock returns using a time-varying parameter VAR with stochastic volatility (TVP-VAR-SV), which is a novel approach to this line of literature. By investigating the net flow-returns relationship from a time-varying perspective, we aim to address the following questions: 
Are foreign investors only trend chasers regardless of the economic conditions in the host market? If this is not the case, what are the economic circumstances that urge such investors to change their trading behaviors? To answer these questions, we must include a control variable that enables us to examine the relationship between foreign equity flows and returns in the context of the economic and financial conditions of the host market. To this end, we include the economic uncertainty index developed by Baker et al. (2016). ${ }^{2}$ Several studies have detected a widespread impact of economic uncertainty on economic activities through several channels. The stock market, in particular, is closely linked to economic uncertainty through direct channels such as volatility and performance of the market (Antonakakis et al. 2013; Liu and Zhang 2015; Arouri et al. 2016) and indirect channels such as investment decisions (Gulen and Ion 2016), financing and production costs (Gilchrist et al. 2014), and interest rate and expected risk premiums (Pastor and Veronesi 2013). Furthermore, the economic uncertainty index could possibly bear some global information as policymaking is globally connected (Faruk et al. 2017). Therefore, the inclusion of economic uncertainty gives the advantage of capturing larger amounts of information at both global and domestic levels, thus potentially turning the VAR model into a factor model.

The estimation of the TVP-VAR-SV model is completed using monthly data from South Korea. As seen in some seminal studies (e.g., Choe et al. 1999, 2005), the South Korean stock market has been one of the most relevant examples to study the behavior of foreign investors. In addition, being one of the largest Asian stock markets with characteristics similar to developed stock markets also makes it particularly attractive to international investors. For this reason, foreign investors' interests in the Korean stock market substantially increased after the 1997-1998 Asian crisis. Foreign investors currently own more than $30 \%$ of the stocks and are allowed to freely trade most of the shares on the exchange except those of public corporations and government-controlled utilities.

This study fundamentally differs from existing studies by accounting for the possible time variations in the interactions between foreign investors and stock returns. Moreover, the inclusion of economic uncertainty in the empirical model is, to the best of our knowledge, unprecedented in this line of literature. Therefore, this study provides a unique in-sample empirical analysis for the interactions between foreign investors and stock returns with respect to the changing economic conditions in an extensively studied market. The empirical analysis reveals several new findings about the trading behaviors of foreign investors. The main results indicate that economic policy uncertainty is an important determinant of the trading behaviors of foreign investors in the South Korean stock market. Their positive feedback trading uniquely emerges during periods of high economic uncertainty, whereas negative feedback trading frequently appears in periods of low economic uncertainty. The feedback trading behaviors mostly appear to be well-timed and often lead the time-varying economic uncertainty except in periods of global crises. The study also documents an asymmetric response of foreign investors to

\footnotetext{
2 The recent emerge of economic policy uncertainty indexes is largely due to the development of text mining methods which have also contributed to the rise of new line of research such as search data from search engines and its connection with stock prices, see Wen et al. (2019) for example.
} 
negative and positive shocks of economic uncertainty. On one hand, such investors turn to positive feedback trading instantly after a negative contemporaneous response of net flows to shocks of economic uncertainty. On the other hand, they slowly move toward negative feedback trading after a positive response of net flows to uncertainty shocks. As for stock returns, the impact of past uncertainty news is found to be economically less significant beyond one month.

The remainder of this study is organized as follows. Section two reviews the related literature. Section three describes the data and the empirical sample. Section four outlines the empirical methodology while section five analyzes the empirical results. The final section summarizes the results and presents concluding remarks.

\section{Literature review}

Theoretically, there are several competing hypotheses to explain the positive relationship between foreign investors and stock returns. The first is the base-broadening hypothesis, which suggests that an expansion of the investor base in the market leads to increased diversification and reduces the risk. With lower risk, investors would require less risk premium causing the equity share price to increase. Clark and Berko (1997) find a similar relationship between foreign equity purchases and market returns in Mexico. Another hypothesis that conjectures the effect of foreign equity inflows on stock returns is the price pressure hypothesis. ${ }^{3}$ The rationale behind this hypothesis is that the shocks of equity capital flow temporarily drive the stock price away from the fundamentals. The third hypothesis is often referred to as the feedback trading hypothesis, according to which the foreign investors are return chasers. Bohn and Tesar (1996) find evidence that US investors move into the market when high returns are foreseen and pull out when the returns are expected to be low. ${ }^{4}$ Therefore, feedback trading by foreign portfolio investors may cause excess market volatility.

Many studies have empirically investigated the joint dynamics of capital flows and equity returns. These studies agree that increases in capital flows raise stock market prices, but there has not been any sort of consensus on whether the price effect is temporary or permanent. Choe et al. (1999) examine the impact of foreign investors on stock returns in Korea from November 30, 1996 to the end of 1997. They find strong evidence that large buy (sell) trades initiated by such investors are indeed associated with a stock price increase (decline), but this trend quickly dies out rendering the effect of feedback trading insignificant.

Froot et al. (2001) use data of daily cross-border flows for 44 countries, of which 16 are developed countries and the remaining 28 are emerging markets. Their study reveals that the capital flows are correlated with future equity returns and currency returns in emerging markets. In addition, the authors detect a small contemporaneous price

\footnotetext{
3 The temporary price pressure associated with individual trades has been difficult to identify empirically (e.g., see Chan and Lakonishok 1995; Keim and Madhavan 1996). Likewise, studies on marketwide equity trades such as Clark and Berko (1997) and Bekaert et al. (2002) could not provide supporting evidence of the price pressure hypothesis.

${ }^{4}$ Similarly, Tesar and Werner (1995a, b) and Brennan and Cao (1997) find pattern of positive feedback trading in the activities of U.S. investors, concluding that the international prices tend to rise when international investors purchase local equities.
} 
impact of the trades of the foreigners in the emerging markets. However, this impact is persistent for the weeks and the months following the foreign investors' trades.

Using the VAR model, Richards (2005) analyzes daily data on total foreign net inflows into six Asian Equity markets over the period 1999-2002. Contrary to Froot et al. (2001), the estimated price impact of unexpected foreign inflows is substantially large and almost completely dwindles within a few days after the trades.

The second strand of the literature suggests that foreign inflows permanently affect local stock markets. Clark and Berko (1997) find evidence of a large impact of the monthly net purchases of Mexican equities by foreigners on stock prices in the period from January 1989 through March 1996. This impact is even larger when the anticipated equity inflows were replaced with unexpected inflows. Clark and Berko (1997) also found no evidence of price reversal after the shocks, indicating that the price change is permanent.

Bekaert et al. (2002) studied the interrelationship among capital flows, returns, dividend yields, and world interest rates in 20 emerging markets and found that a shock in equity flows contemporaneously increases the stock price level by $6 \%$. The empirical evidence of this study also points to a positive and persistent impact over the 60-month horizon of the response to flow shocks.

Dahlquist and Robertsson (2004) also employ the impulse response analysis to examine the impact of foreigners' purchases and sales on the stock returns of Swedish firms. Similar to Bekaert et al. (2002), their empirical results indicate a positive contemporaneous correlation between flows and returns and no reversal of price impact throughout the sample period. More specifically, they find that the immediate price impact increases gradually in the following months.

Despite the disagreement on whether the impact of foreign equity flows on returns is permanent (price impact) or temporary (price pressures), the positive feedback trading by foreigners and a contemporaneous impact of foreign equity flows on stock returns has been a common finding in the aforementioned studies. The findings documented by other studies, particularly those on emerging Asian markets, have been consistent with this relationship irrespective of the frequency of the data (e.g., Griffin et al. 2004; Chai-Anant and Ho 2008; Chai-Anant 2003; Karolyi 2002; Tayde and Rao 2011; Jeon and Moffet 2010; Hong and Lee 2011; Kim and Jo 2019; Porras and Ülkü 2015; Samarakoon 2009). However, some recent studies have contradicted the evidence of the positive relationship between foreign equity and stock returns. Using monthly data, Hau and Rey (2004) find evidence of a negative relationship between equity portfolio flows of the United States and equity returns of five industrial economies. The negative relationship is often hypothesized as "portfolio rebalancing" behavior, that is, investors reallocate funds away from assets in their portfolio that have appreciated in value toward those that have depreciated, to restore the optimal portfolio balance (Chai-Anant and Ho 2008). In a recent study, Ülkü and Weber (2014) document the existence of such a relationship in the stock markets of Taiwan and Thailand. This relationship is also observed in the behavior of foreign investors and returns of the stock markets in emerging Europe (Ülkü and Ikizlerli 2012; Ülkü and Karpova 2014; Ülkü 2015). 
Table 1 Descriptive statistics and unit root tests

\begin{tabular}{lcccccc}
\hline Variables & Mean & Median & SD & Jarque-Bera & ADF stats & PP stats \\
\hline EPU & 125.6682 & 115.4781 & 61.03046 & $203.6935^{*}$ & $-6.0873^{*}$ & $-5.987031^{*}$ \\
NEF & 0.048597 & 0.024622 & 0.33462 & $272.5904^{*}$ & $6.85734^{*}$ & $-9.943895^{*}$ \\
R & 0.537039 & 0.793852 & 6.680249 & $24.10784^{*}$ & $14.5118^{*}$ & $-14.52511^{*}$
\end{tabular}

The asterisk * implies statistical significance at the $1 \%$ level. ADF and PP are abbreviations for the Augmented Dickey-Fuller test and Phillips-Perron test, respectively

\section{Data and descriptive statistics}

Our empirical investigations are carried out using monthly time series of stock returns (R), net foreign equity flows (NEF), and economic uncertainty index (EPU) from South Korea. The descriptive statistics of the variables along with the results of unit root tests at level are presented in Table 1. The data sample spans the period between January 1999 and December 2018. Although partially opened to foreigners in 1992, full-scale liberalization of the South Korean market was only achieved in May 1998. Since then, the Korean stock market has become increasingly attractive to international investors. Before the 1997 Asian crisis, foreign ownership of Korean stocks accounted for only $12.3 \%$ of total stocks. This share grew to $16.36 \%$ at the full-scale liberalization event, then jumped to $20.22 \%$ in 1999. Foreign investors' share of Korean stocks continued to increase at a rapid pace reaching its peak at $42 \%$ in 2004 . Throughout the sample, foreigners' ownership of stocks averages around 30\% of total stocks on the exchange. It should be noted that the study period is free from foreigners' trade restrictions and post-liberalization effects. As suggested by Ülkü and Ikizlerli (2012), a sample with such characteristics is more suitable to study true trading behaviors of foreign investors.

The data on stock price index and equity trading by foreigners are freely accessible on the website of the Korean stock exchange market. The logarithmic returns are derived from the KOSPI composite index. The variable used to proxy for NEF is the difference between the marketwide purchases and sales by foreign investors. The difference in the foreigners' equity trading is expressed as a percentage of the free-float market capitalization.

The economic policy uncertainty (EPU) index for South Korea is obtained from the policy uncertainty website. ${ }^{5}$ This uncertainty index is domestically measured based on the newspaper coverage of policy-related economic uncertainty as explained in Baker et al. (2016). However, since domestic economic uncertainty can be driven by global turbulent events, it is not surprising to find significant co-movements between global and domestic economic uncertainty indexes. These co-movements may be even more profound in the case of a small open economy. As illustrated in Fig. 1, the remarkable comovements and the highly positive correlation between the indexes of global economic uncertainty and South Korea's economic uncertainty strongly suggest that the domestic uncertainty in the South Korean market is highly integrated with global uncertainty. ${ }^{6}$ The simultaneity between the two indexes is certainly a result of the close relationship

\footnotetext{
${ }^{5}$ www.policyuncertainty.com

${ }^{6}$ Chicago Board Options Exchange's CBOE volatility index (VIX) and KOSPI's volatility index are also highly positively correlated ( $\rho_{C B O E^{\prime}}$ VVIX, KOSPI's VIX $\left.=0.706\right)$, which further confirm our argument.
} 


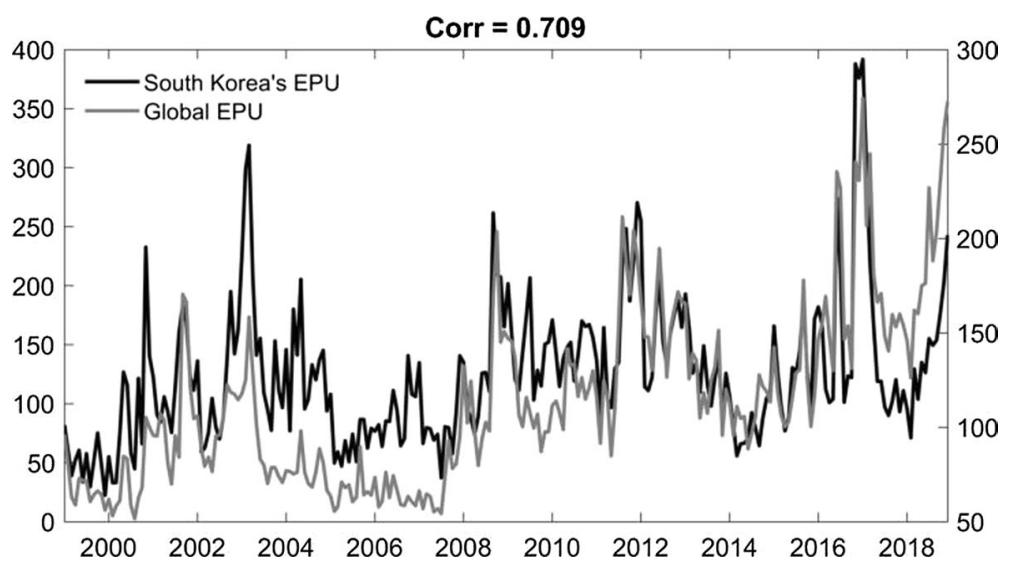

Fig. 1 Economic uncertainty indexes

between the South Korean economy and advanced economies. This relationship has been largely established through financial channels. As global uncertainty may be of primary concern to the international investors, this likely means that such investors should be familiar with the nature of uncertainty in the Korean market to some degree. Consequently, this may undermine the impact of the informational disadvantage on foreign investors. Therefore, it is unlikely that foreigners only follow positive feedback trading, particularly in marketwide equity trades. Even if they follow positive feedback trading, it could be for reasons other than the informational disadvantage. Recall that some studies such as Albuquerque et al. (2009) do not attribute foreign investors' positive feedback trading to informational disadvantage.

The choice of using monthly data is essentially driven by data availability and empirical requirements of the TVP-VAR-SV model. As it is known, economic uncertainty indexes are typically reported at monthly frequency. Empirically, monthly data fulfill the requirements of estimating the structural shocks in the TVP-VAR-SV model. Nakajima et al. (2011) note that the log of variance for the structural shocks is modeled to follow a random walk process, which is non-stationary. In contrast, in the literature on finance log volatility is often formulated to follow a stationary process. Therefore, it would be undesirable to analyze long series behavior of market products such as financial daily data using a random walk process. Moreover, almost all the studies that use daily data in the context of emerging Asian markets have commonly referred to the evidence of positive feedback trading. Hence, it is highly improbable that the outcome will be any different.

\section{Empirical methodology}

\section{Time-varying parameter VAR model with stochastic volatility}

The main advantage of the TVP-VAR-SV model is that the parameters of the VAR matrix are allowed to change over time by incorporating the stochastic volatility in the estimation process. The Bayesian VAR, particularly TVP-VAR, models have been consistently found to outperform the standard VAR models (e.g., see Lai and Wang 2014; Kumar 2010). Following the procedures described in Nakajima (2011), we estimate a time-varying parameter VAR (TVP-VAR) with stochastic volatility. 
To describe aforementioned procedures, we first consider a structural VAR model with the following formula

$$
A y_{t}=F_{1} y_{t-1}+\cdots+F_{s} y_{t-s}+\mu_{t}, t=s+1, \ldots, n,
$$

where $y_{t}$ is a $k \times 1$ vector of endogenous variables, $A, F_{1}, \ldots, F_{s}$ are $k \times k$ matrices of coefficients.

The disturbance $\mu_{t}$ is a $k \times 1$ structural shock and, it is assumed that $\mu_{t} \sim N(0, \Sigma \Sigma)$, where

$$
\Sigma=\left(\begin{array}{cccc}
\sigma_{1} & 0 & \cdots & 0 \\
0 & \ddots & \ddots & \vdots \\
\vdots & \ddots & \ddots & 0 \\
0 & \cdots & 0 & \sigma_{k}
\end{array}\right)
$$

The simultaneous relations of the structural shock are specified by recursive identification, assuming that $A$ is lower-triangular,

$$
A=\left(\begin{array}{cccc}
1 & 0 & \cdots & 0 \\
a_{21} & \ddots & \ddots & \vdots \\
\vdots & \ddots & \ddots & 0 \\
a_{k 1} & \cdots & a_{k, k-1} & 1
\end{array}\right)
$$

Model (1) can be rewritten as the following reduced-form VAR model:

$$
y_{t}=B_{1} y_{t-1}+\cdots+B_{s} y_{t-s}+A^{-1} \Sigma \varepsilon_{t}, \varepsilon_{t} \sim N\left(0, I_{k}\right),
$$

where $B_{i}=A^{-1} F_{i}$, for $i=1, \ldots, s$. Stacking the elements in the rows of the $B_{i}$ 's to form $\beta\left(k^{2} \times 1\right.$ vector $)$, and defining $X_{t}=I_{s} \otimes\left(y_{t-1}^{\prime}, \ldots, y_{t-s}^{\prime}\right)$ where $\otimes$ denotes the Kronecker product, the model can be written as

$$
y_{t}=X_{t} \beta+A^{-1} \Sigma \varepsilon_{t}
$$

The parameters of Model (1) are all time-invariant, but they can be allowed to change over time by extending it to the TVP-VAR model with stochastic volatility specified by

$$
y_{t}=X_{t} \beta_{t}+A_{t}^{-1} \Sigma_{t} \varepsilon_{t}, t=s+1, \ldots, n,
$$

where the coefficients $\beta_{t}$, and the parameters $A_{t}$, and $\Sigma_{t}$ are all time varying. There are many ways to model the process for these time-varying parameters.

Following Primiceri (2005), let $a_{t}=\left(a_{21}, a_{31}, a_{32}, a_{41}, \ldots, a_{k, k-1}\right)^{\prime}$ be a stacked vector of the lower-triangular elements in $A_{t}$ and $h_{t}=\left(h_{1 t}, \ldots, h_{k t}\right)^{\prime}$ with $h_{j t}=\log \sigma_{j t}{ }^{2}$, for $j=1, \ldots, k, t=s+1, \ldots, n$. The parameters in (9) are assumed to follow a random walk process as follows:

$$
\begin{aligned}
& \beta_{t+1}=\beta_{t}+\mu_{\beta t}, \\
& a_{t+1}=a_{t}+\mu_{a t}, \\
& h_{t+1}=h_{t}+\mu_{h t},
\end{aligned}
$$




$$
\left(\begin{array}{c}
\varepsilon_{t} \\
\mu_{\beta t} \\
\mu_{a t} \\
\mu_{h t}
\end{array}\right) \sim N\left(0,\left(\begin{array}{cccc}
I & 0 & 0 & 0 \\
0 & \Sigma_{\beta} & 0 & 0 \\
0 & 0 & \Sigma_{a} & 0 \\
0 & 0 & 0 & \Sigma_{h}
\end{array}\right)\right)
$$

for $\quad t=s+1, \ldots, n, \quad$ where $\quad \beta_{s+1} \sim N\left(\mu_{\beta 0} \mu, \Sigma_{\beta 0}\right), \quad a_{s+1} \sim N\left(\mu_{a 0}, \Sigma_{a 0}\right) \quad$ and $h_{s+1} \sim N\left(\mu_{h 0}, \Sigma_{h 0}\right)$.

As in Nakajima (2011), the recursive identification of the VAR system assumes a lowertriangular matrix for $A_{t}$, and $\Sigma_{a}$ and $\Sigma_{h}$ are assumed to be diagonal matrices.

\section{Estimation procedures of time-varying parameter VAR}

The TVP-VAR-SV is estimated via the Markov Chain Monte Carlo (MCMC) method. To illustrate this process, let $y=\left\{y_{t}\right\}_{t=1}^{n}$, which represents the data, and $\omega=\left(\Sigma_{\beta}, \Sigma_{a}, \beta_{h}\right)$. The prior probability density is set as $\pi(\omega)$ for $\omega$. Given the data $y$, the samples are drawn from the posterior distribution $\pi(\beta, a, h, \omega \mid y)$ following the MCMC algorithm:

1. Initialize $\beta, a, h$ and $\omega$.

2. Sample $\beta \mid a, h, \Sigma_{\beta}, y$.

3. Sample $\Sigma_{\beta} \mid \beta$.

4. Sample $a \mid \beta, h, \Sigma_{a}, y$.

5. Sample $\Sigma_{a} \mid a$.

6. Sample $h \mid \beta, a, \Sigma_{h}, y$.

7. Sample $\Sigma_{h} \mid h$.

8. Go to 2 .

The simulation smoother of de Jong and Neil (1995) and Durbin and Koopman (2002) is used to sample the time-varying coefficients $\beta$ and parameter $a$ in steps 2 and 4, stochastic volatility $h$ in step 6 is sampled using Watanabe and Omori's (2004) multi-move sampler. Steps 3, 5, and 7 are simply sampled from a Wishart or Gamma distribution under conjugate priors (see Nakajima (2011) and Nakajima et al. (2011) for more details). The prior setups and the MCMC simulations of posterior distributions for our estimations of the TVP-VAR-SV parameters are summarized in Appendix A.

\section{Identification of structural shocks}

The impulse response function is one of the most efficient methods to capture the interdependent dynamics of data. In terms of the net flow-return relationship, the contemporaneous effect is implied when the response starts at zero lag. The positive (negative) lagged responses of flows to return shocks indicate positive (negative) feedback trading, whereas positive lagged responses of returns to flow shocks imply that the flows can be a predictive factor of future returns. The inference of permanent impact (price impact) requires a continuation of the positive response of returns to flow shocks. This impact is considered temporary (price pressure) if any subsequent reverse follows the contemporaneous positive response. Most previous studies rely on standard Cholesky decomposition to test for the existence of such behaviors in the interactions between the NEF and stock returns. As previously mentioned, the TVP-VAR-SV model implements a similar recursive identification scheme to estimate the contemporaneous relationship. Such 
an identification scheme follows a causal ordering in which variables of lower ordering do not contemporaneously influence those of higher order. However, the ordering of the variables is still a notorious problem in this line of literature. Following Hasbrouck (1991), many studies order net flows before returns assuming that returns can only affect net flows with lag. A major drawback of this assumption is that it excludes any contemporaneous effect of returns on foreign equity flows, which can be theoretically valid in the daily data. Nevertheless, Griffin et al. (2004), Richards (2005), and Ülkü and Weber (2014) provide strong evidence for the positive response of foreign investors to the local past returns at the daily frequency. In light of these results, Hasbrouck's (1991) assumption seems irrelevant to data at the monthly frequency as suggested by Porras and Ülkü (2015). Following the latter, we use alternative orders by ordering stock returns last when the contemporaneous response of returns is of interest; the order then is reversed to allow for the contemporaneous response of NEF to stock returns. The economic uncertainty index is placed first in both alternative orders. This ordering is consistent with financial variables moving quickly in response to economic conditions as assumed by Sims and Zha (2006).

\section{Analysis of the empirical results Preliminary analysis}

In this section, we test for the presence of structural changes in the time series of stock returns and NEF. To this end, we use the iterated cumulative sum of squares (ICSS) algorithm developed by Inclan and Tiao (1994). The ICSS algorithm iteratively searches for multiple change points in the variance at different segments of the series. It is essentially based on the centered version of the cumulative sum of squares presented by Brown et al. (1975). The ICSS algorithm is configured to have a significance level of 5\%. For this level, Inclan and Tiao (1994) provide a numerically simulated asymptotic critical value equal to 1.358 . The structural changes identified by the ICSS algorithm are displayed in Fig. 2.

The first notable observation is that structural changes distinctively appear around the tumultuous events, particularly the global financial crisis of 2008. In our sample, the period from January 1999 up to November 2001 was the most volatile in the South Korean stock market. This high volatility is most likely caused by the severe recession in the global high-tech industry ${ }^{7}$ in 2001 . Moving forward to the period of the global financial crisis in 2008, the volatility of stock returns further decreased in the last stages of this crisis in July 2009. The NEF appear to be highly unstable compared to stock returns and more sensitive to external shocks. Similar to stock returns, the volatility of NEF indicates major changes around the global recession of the high-tech industry in 2001 and the global financial crisis of 2008. Moreover, another structural change of net equity flows in the Korean stock market appears in October 2013. This change is perfectly concurrent with the rumors of the US Federal Bank tapering its fund rate in late 2013. This

\footnotetext{
7 The East-Asian countries were already in a recovery period from the repercussions of the 1997-1998 Asian crisis, but were hit by another recession shortly afterwards caused by the high-tech industry in the United States. As a result, many East-Asian countries suffered a sharp downturn in exports and output growth.
} 

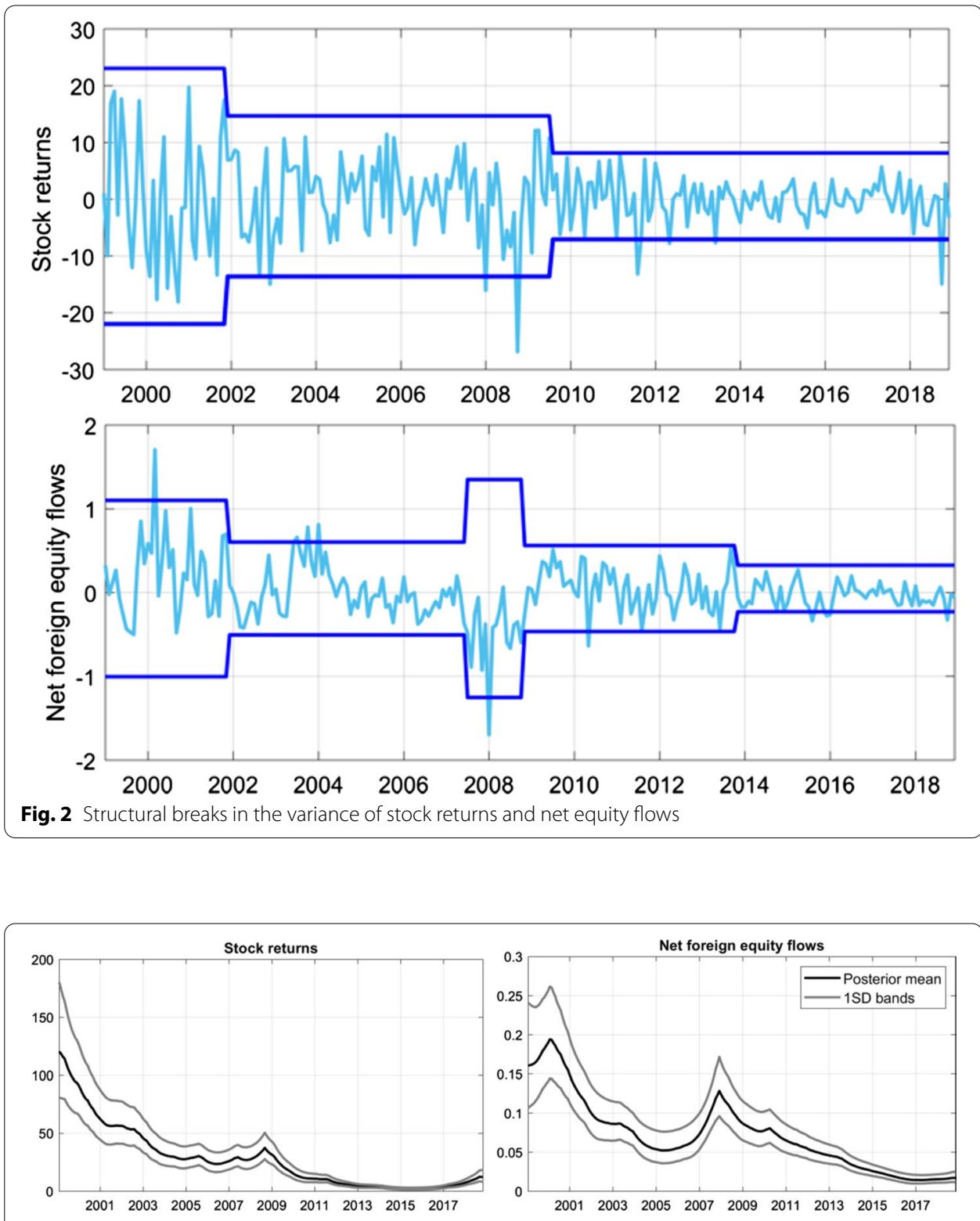

Fig. 3 Time-varying stochastic volatility

event, which has become known as "Taper Tantrum" generated worldwide shock waves that severely affected many emerging market economies.

\section{The time-varying stochastic volatility}

The stochastic volatility is a critical component of the TVP-VAR-SV model, it allows the time-varying coefficients to adapt to possible variations in the disturbances signaled in the underlying time series. Nakajima et al. (2011) state that time-varying volatility contributes to the VAR estimation, identifying the structural shock with the appropriate variance of the shock size. The posterior estimates of stochastic volatility for stock returns and NEF in South Korea are plotted in Fig. 3. As can be seen, volatility spikes are 


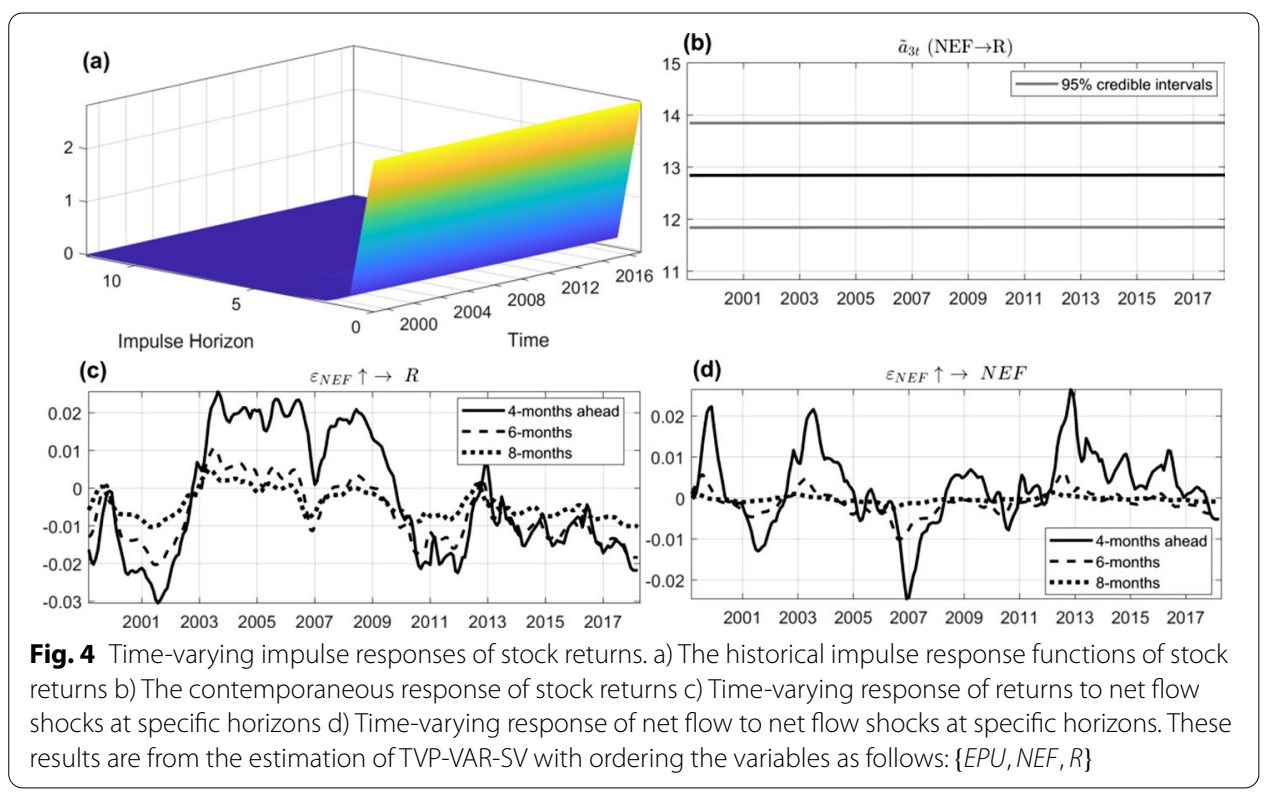

strikingly obvious around the periods of the global recession of the high-tech industry in 2001 and the global financial crisis of 2008. The volatility spikes around the former are notably higher compared to the period of the latter. In addition, the stochastic volatility of NEF and stock returns in South Korea starts strong at the beginning of the sample period, then follows a downward trend thereafter. Interestingly, there is a significant joint reduction of stochastic volatility starting from 2011 in stock returns and NEF. In general, the dynamics of stochastic volatility are somewhat similar to the incremental shrinkage in the variances given earlier by the results of the ICSS algorithm.

\section{Foreign investors' impact on stock returns}

The time-varying impulse response is one of the main characteristics of the TVP-VARSV model. The model offers two methods to present such responses. In the first method, historical impulse response functions can be drawn in a three-dimensional form by computing the recursive innovations of the variables using the time-varying coefficients from the current date to the future period. At each time point, there will therefore be a different set of impulse response functions. In the second method, the responses can be drawn in a time series manner by showing the size of the impulses for specific horizons over time. In the setting of Nakajima's (2011) estimations of the TVP-VAR-SV model, the response corresponds to a shock size equal to the average of stochastic volatility of each variable in the VAR system. Since the computation of the impulse response functions is based on time-variant parameters, the effects and contributions of shocks may also change over time.

The time-varying response of stock returns to net flow shocks are illustrated in Fig. 4. While the historical impulse responses and contemporaneous relations, shown by graphs a and b, respectively, initially indicate a time-invariant positive contemporaneous impact of NEF on stock returns, graph c shows a time-varying propagation mechanism of the net flow shocks. The propagation mechanism of the net flow shocks is apparently 
completely dependent on the financial and economic conditions of the stock market. More precisely, the time-varying impact of net flow shocks on stock returns quickly turns to a negative impact during most of the crises, especially the 2001 recession of the high-tech industry and the European sovereign debt crisis in 2010. However, it took a slightly longer horizon to become negative during the 2008 global financial crisis. Note that during the latter, the impact of NEF is not as severe as the other crises. The results also imply that NEF positively predict stock returns, this finding is consistent throughout the sample period and statistically significant, as can be seen in graph b. Moreover, the positive forecast ability of net flows to stock returns is limited to a two-month horizon ahead during the crises, but it can persist to longer horizons at some time points. Notably, during the period from 2003 up to the break-out of the global financial crisis, the impact of net flows remains positive over 8-month horizon ahead. This means that foreign investors enjoyed a longer time window of profitable trades during this period, whereas they have a short time window of positive returns following their trades during crises. Surprisingly, the positive short-horizon forecast ability of net flows becomes more frequent after the "Taper Tantrum" event in May 2013. From this event and forward, the South Korean economy experienced a sharp reduction in foreign capital inflows coupled with a slowdown of economic growth. As shown in Fig. 2, the foreign investors' net equity trading also began to decline since this event. The weak growth potentials possibly affected the performance of the stock market and led to decreased trading activities by foreign investors. Graph d shows the persistence of net flows, which is a result of net flow response to its own shocks, and provides further insight into the positive contemporaneous relationship between foreign investors and stock returns. It shows that the positive forecast ability is mostly due to the persistence in net flows. This finding is essentially derived from the significant co-movement between time-varying responses of returns and net flows at the horizon of 4-month ahead of the shock. It is also important to note that the co-movements of net flows and returns' time-varying responses appear at other subsequent horizons. This finding seems to support the hypothesis of "price pressure" rather than "price impact".

Ülkü (2015) suggests that the evidence of forecast ability may imply a marginal information advantage or a sophisticated response to new information by foreign investors. Based on our findings, the time variations in the positive forecast ability according to the global and local economic conditions, specifically during the last period of slow economic growth, may indicate that foreign investors are strongly informed about the macroeconomic fundamentals of the host market. Foreign investors may still lack local information as suggested by Brennan and Cao (1997) and Griffin et al. (2004). Nonetheless, their equity trading activities are based on superior macroeconomic knowledge. Ülkü and Ikizlerli (2012) and Ülkü (2015) establish this assumption through foreign investors' positive contemporaneous response to global stock returns. Our findings further support this assumption based on the adjustability of positive forecast ability of net flows according to the macroeconomic conditions.

\section{Feedback trading and the role of economic uncertainty}

The time-varying reactions of foreign investors to return shocks are displayed in Fig. 5. Note that these results are derived from estimating TVP-VAR-SV with ordering NEF 

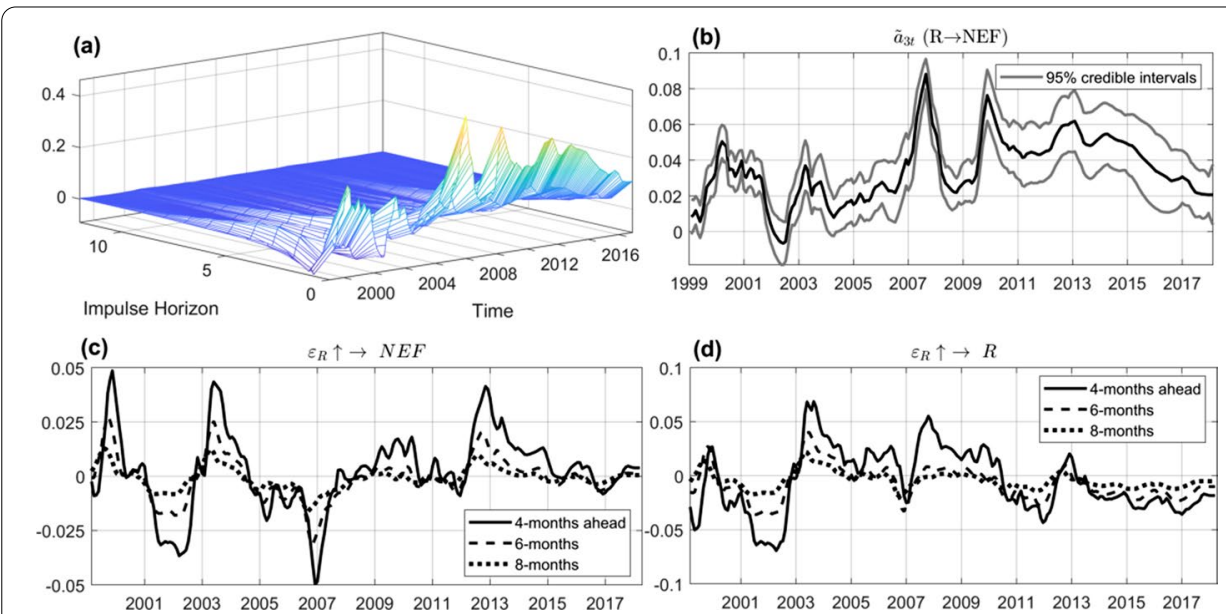

Fig. 5 Time-varying impulse responses of NEF. a) The historical impulse response functions of net flows b) The contemporaneous response of net flows c) Time-varying response of net flows to return shocks at specific horizons d) Time-varying response of returns to return shocks at specific horizons. These results are from the estimation of TVP-VAR-SV with ordering the variables as follows: $\{E P U, R, N E F\}$

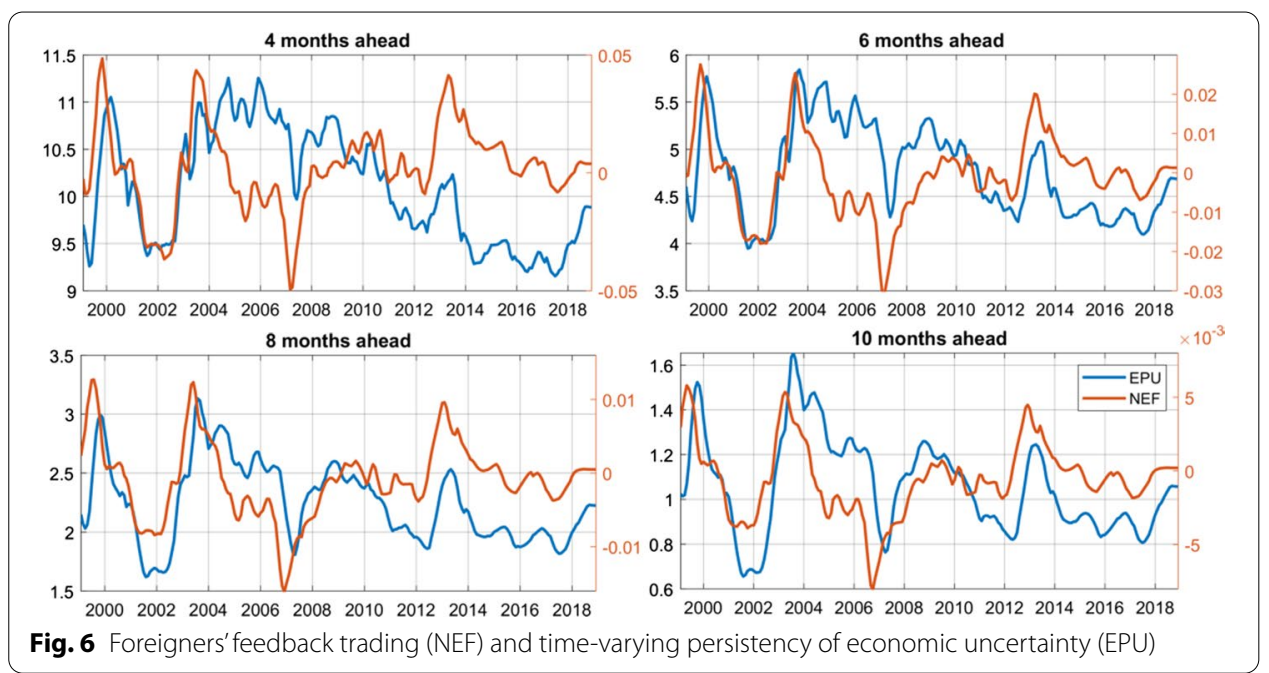

after stock returns. It is important to note the contemporaneous impact of returns on net flows in graph $\mathrm{b}$ while explaining the trading behaviors at the subsequent horizons from graph c. As can be seen in the two graphs, there are some drastic changes in the trading behavior of foreign investors. To make more sense of these changes, we plot the foreign investors' time-varying responses to return shocks along with the time-varying economic uncertainty as shown in Fig. 6. The time-varying economic uncertainty is a result of its response to its own shocks, which can also be interpreted as persistence of economic uncertainty. The time-varying responses of both variables are presented at different impulse horizons.

Several observations from Fig. 5 are worth highlighting. First, the foreigners in the South Korean stock market are often initially trend chasers, as indicated by the timevarying positive contemporaneous responses of net flows in graphs a and b. Notably, 
the foreign investors are more aggressively trend chasers during the crises, particularly the 2008 financial crisis and the European sovereign debt crisis in 2010. The aggressive trend-chasing behaviors, during these periods specifically, are undoubtedly a result of the rampant equity sell-off caused by the worldwide collapse of stock markets during the aforementioned crises. Second, the time-varying positive contemporaneous response of net flows frequently reverses to negative response, which amounts to behaviors of negative feedback trading. There is abundant evidence of such trading at the subsequent horizons. Based on the results in graph c, the bulk of the time-varying negative feedback trading is observed in the fourth month after the shock. However, the lagged negative impact of stock returns on net flows can be observed, although seldomly, within one or two months after return shocks; this quick reverse is exclusively found during the year 1999 and the period between February 2001 and September 2002. Third, foreigners' trading behaviors sometimes appear to be following a specific pattern of feedback trading. In other words, the contemporaneous response of the net flows can be either negative or positive with no reverse of the sign over the entire impulse horizon. For instance, we find evidence that the foreign investors are purely positive feedback traders during several sub-periods: March 2003-February 2004, May-September 2009, and September 2012-August 2014, whereas the response of net flows is entirely negative during the period April-September 2002. Finally, examining the results presented in graphs $\mathrm{c}$ and $\mathrm{d}$ reveals that the foreign investors tend to be negative feedback traders when the movements of stock returns are weakly persistent.

The latter finding may seem consistent with the analogy provided by Ülkü (2015), who suggests that the positive feedback trading is initially prompted by the response to host market information, then the negative feedback trading appears once the response to this information is completed. However, the results presented in Fig. 6 indicate that the foreigners' feedback trading is largely dependent on the time-varying perceptions of economic uncertainty. According to these results, the foreigners' negative feedback trading prevails when the persistence of economic uncertainty becomes weakly sustainable. On the other hand, the behavior of foreigners' positive feedback trading exceptionally appears during periods of high economic uncertainty. Interestingly, the negative contemporaneous response of net flows observed earlier is associated with extremely low levels of economic uncertainty. Recall that negative feedback trading is equivalent to informedness. This means that foreign investors act as information contributors when economic uncertainty is weak, but they trend-chase while the uncertainty about the economic policy is strong. In fact, their feedback trading mostly appears to be well-timed and often leads the time-varying economic uncertainty during most of the sample period. As expected, the periods of global crises are an exception. This finding sharply contrasts the theories of the informational disadvantage of foreign investors (Brennan and Cao 1997; Griffin et al. 2004; Brennan et al. 2005). The findings can also be considered an extension to the evidence provided by some recent studies on South Korea such as Ülkü (2015) and Ülkü and Weber (2014). the aforementioned studies indeed find strong evidence of lagged negative feedback trading in South Korea. However, their results exclude the possibilities of the negative contemporaneous response of net flows to stock returns and persistent positive feedback trading. Empirical evidence for such patterns of equity trading behaviors are distinctively apparent in our results despite the wide prevalence of the 


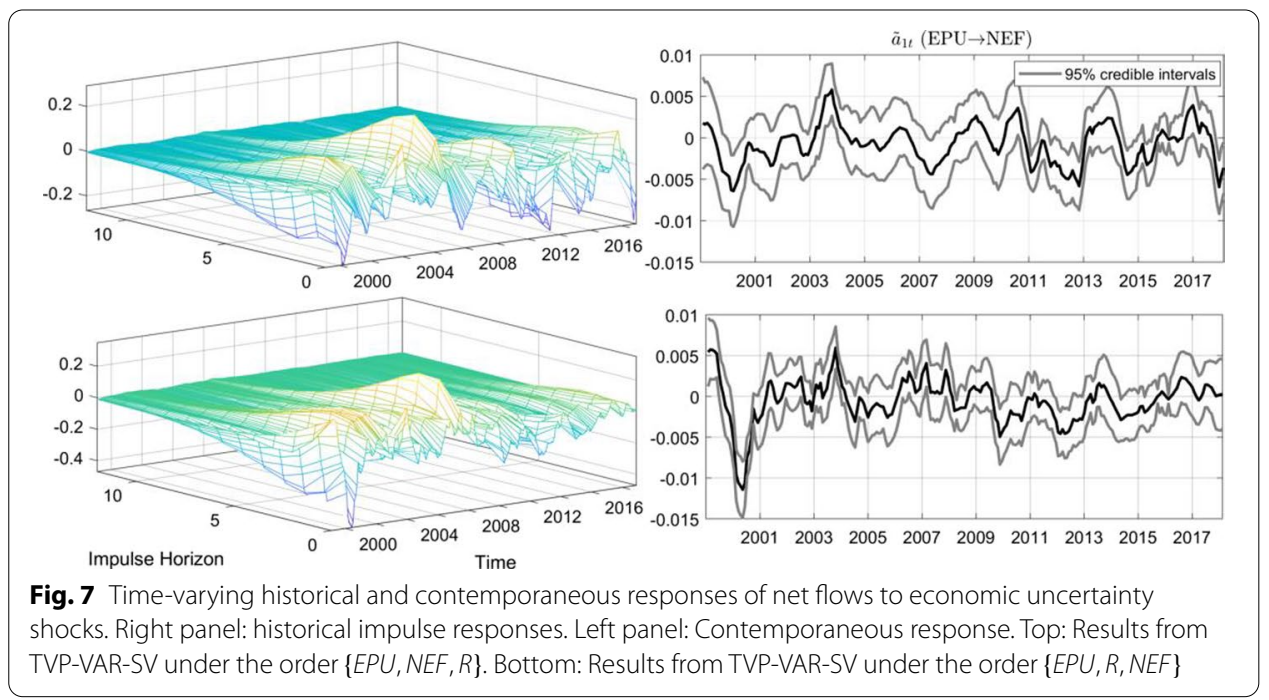

lagged negative feedback trading. Furthermore, we find little evidence that supports the predictions of Hau and Rey's (2004) portfolio rebalancing model. This model predicts a negative contemporaneous correlation between net flows and stock returns caused by selling appreciated stocks in the host market to mitigate exchange rate risk. ${ }^{8}$ The main implication of Hau and Rey's (2004) model, that is, the negative contemporaneous impact, is found to be short-lived and is highly driven by extremely low levels of economic uncertainty. The inaccurate predictions of Hau and Rey's (2004) model are probably due to failure to control for a common driver of the exchange rate, equity returns, and net flows. Alternatively, we suggest that the flow orders in the foreign exchange market that correspond to foreigner's equity portfolio rebalancing are probably simultaneously driven by the level of economic uncertainty in the host market.

\section{Impact of uncertainty on foreign investors and stock returns}

The time-varying impact of economic uncertainty shocks on foreign investors and stock returns are illustrated in Figs. 7 and 8, respectively. We report the results of the two previously explained alternating orders. Although the time-varying impulse responses of net flows to uncertainty shocks are largely similar, the time-varying responses of stock returns to uncertainty shocks differ sharply across the two orders. Under the order of $\{E P U, N E F, R\}$, the time-varying response of stock returns is mixed with negative and positive contemporaneous responses throughout the sample period. Meanwhile, stock returns always respond negatively to shocks of uncertainty under the order of $\{E P U, R, N E F\}$. However, further results reported in Fig. 10 in Appendix B show that these differences are limited to the contemporaneous responses; the time-varying

\footnotetext{
$\overline{8}$ The scenarios of portfolio rebalancing in Hau and Rey's (2004) model are straightforward. Continuous portfolio flows appreciate the foreign-exchange rate and create foreign-equity market excess returns. This could lead to an excessive foreign-equity market returns relative to home-equity market returns; in this case, foreign investors rebalance their portfolio to reduce exchange rate exposure. Moreover, appreciation of foreign market currency increases the asset share of the foreign investor in the foreign market, thus increasing exposure to exchange risk, which urges portfolio rebalancing. Consequently, foreign investors' sales of holdings in the host market exert downward pressures leading to depreciation of the foreign currency and restoring the initial weight of foreign investor's portfolio.
} 


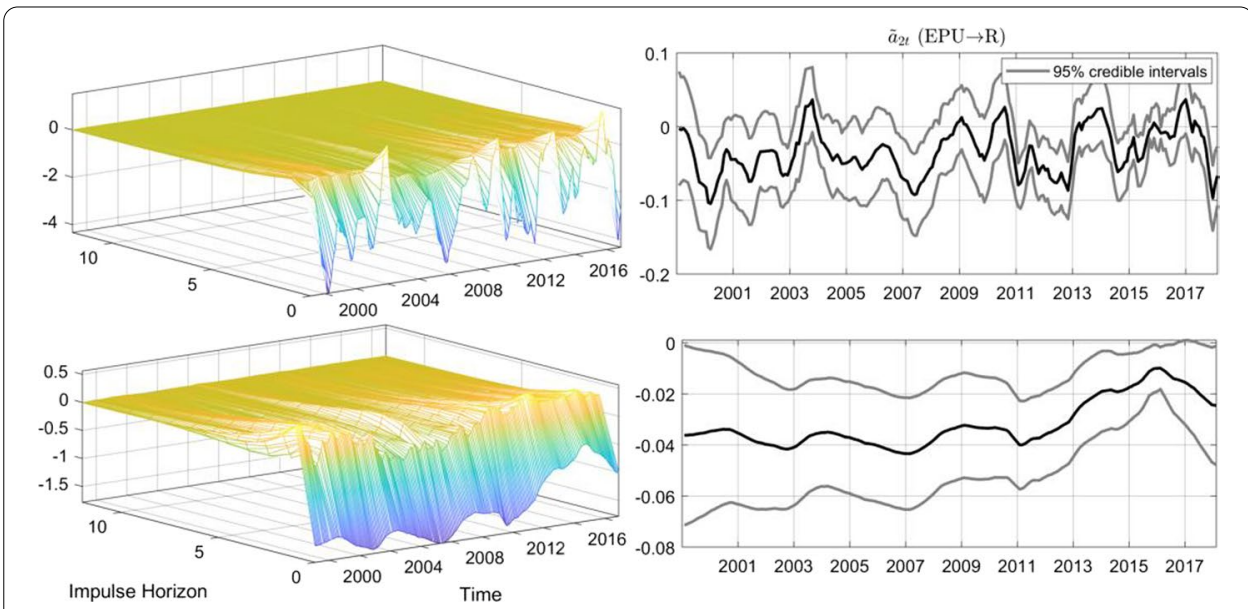

Fig. 8 Time-varying historical and contemporaneous responses of stock returns to economic uncertainty shocks. Right panel: historical impulse responses. Left panel: Contemporaneous response. Top: Results from TVP-VAR-SV under the order $\{E P U, N E F, R\}$. Bottom: Results from the TVP-VAR-SV under the order $\{E P U, R, N E F\}$

responses of stock returns at the subsequent horizons are quite similar across the two orders. Note that the time-varying contemporaneous responses of net flows and stock returns under the order of $\{E P U, N E F, R\}$ are identical to each other. More importantly, the results in Fig. 8 indicate that a large fraction of uncertainty impact on stock returns quickly diminishes within one month after the shock irrespective of the order. In other words, the past uncertainty news bears a significantly smaller economic impact on stock returns beyond one month.

On the other hand, economic uncertainty sometimes appears to have a long-lasting impact on net flows, particularly during periods of global crises, although the extent of this impact is strongly dependent on the type of uncertainty shock. The longest-lasting positive impact of uncertainty on net flows is notably observed prior to the outbreak of the 2008 global financial crisis. Overall, the negative impact of uncertainty shocks on net flows is found to be contemporaneously stronger, yet less persistent, and relatively less strong than the impact of positive shocks at the subsequent horizons. This finding also points to an asymmetric response of foreign investors to different shocks of economic uncertainty. More specifically, foreign investors may sluggishly respond to positive shocks of economic uncertainty compared to negative shocks at some time points. However, they are eventually more driven by positive shocks of economic uncertainty than the negative ones in longer horizons. It can therefore be concluded that NEF can either co-move or inversely move with EPU. Most of the empirical analyses of static models have so far uniformly reported an adverse impact of economic uncertainty on foreign investments (e.g., see Canh et al. 2020; Choi et al. 2020; Rivoli and Salorio 1996). In contrast, we find that economic uncertainty impact is not limited to creating adverse shocks on foreign equity investments. 
Another aspect to consider is the direct connection between net flows' response to economic uncertainty and foreign investors' feedback trading. Accordingly, we find that lagged negative (positive) response of net flows to uncertainty is associated with lagged positive (negative) feedback trading. Part of these results is reported in Fig. 11 in Appendix B. Note that the inverse relationship between net flows' response to uncertainty and foreign investors' feedback trading becomes regularly apparent starting from the second or third month after the uncertainty shocks. The appearance of this type of relationship distinguishably at the subsequent horizons is due to the asymmetric impact of economic uncertainty on net flows. As previously discussed, foreign investors respond quickly to negative shocks of uncertainty to net flows, which leads to instant positive feedback trading. Contrarily, foreign investors slowly move toward negative feedback trading after a positive contemporaneous response of net flows to uncertainty shocks. This also explains the wide prevalence of time-varying contemporaneous positive feedback trading as documented earlier in the analysis of foreign investor's feedback trading. The asymmetric response of foreign investors could possibly be explained by the flows of net foreign equity investments into the market despite the increase of economic uncertainty. ${ }^{9}$ In this case, the foreign investors may forcibly be trend chasers as market trends are unpredictable due to uncertainty about fiscal, regulatory, and monetary policies. This explanation is more reliable under the results of estimating TVP-VAR-SV with the order of $\{E P U, N E F, R\}$, which reveals that net flows and stock returns have similar contemporaneous responses to economic uncertainty shocks. Foreign investors would move toward negative feedback trading as economic uncertainty begins to decline.

\section{Conclusion}

The net flow-return relationship and the trading behaviors of foreign investors have been extensively studied, with attention mostly focused on stock markets of advanced and emerging economies. In this framework, the existing literature analyzes the net flow-returns relationship using models of structural VAR whose parameters are timeinvariant. However, stock returns and foreign equity flows are known to be susceptible to structural breaks caused by external shocks. Therefore, assuming constant dynamics between NEF and equity returns may be unrealistic and empirically too restrictive to the parameters of the VAR model. We investigate the interactions between foreign investors and stock returns with respect to economic uncertainty in the South Korean stock market from a time-Varying perspective. The empirical estimations are conducted using the TVP-VAR-SV model described in Nakajima (2011). To the best of our knowledge, this study is the first to employ a news-based measure of economic uncertainty along with the model of time-varying parameter VAR to investigate the trading behaviors of foreign investors. The empirical results enrich the literature with several new findings about the foreign investors' trading behaviors. First, we demonstrate that economic uncertainty is a significant driver of foreign investors' trading behaviors. During periods of high economic uncertainty, such investors become trend chasers, which results in

\footnotetext{
9 The inflows of foreign equity investments to market during periods of elevated economic uncertainty is a strong possibility given the evidence that net foreign equity flows can either co-move or inversely move with economic uncertainty as previously highlighted.
} 
positive feedback trading. Foreign investors then move toward negative feedback trading as economic uncertainty begins to decline. Second, feedback trading mostly appears to be well-timed and often leads the time-varying economic uncertainty except in the periods of global crises. Third, the empirical findings indicate that lagged negative (positive) response of net flows to uncertainty is coupled with lagged positive (negative) feedback trading. Fourth, the study documents asymmetric behaviors of foreign investors with regard to positive and negative shocks of uncertainty. The foreign investors turn to positive feedback trading instantly after a negative contemporaneous response of net flows to shocks of economic uncertainty. In contrast, they move slowly toward negative feedback trading after a positive response of net flows to economic uncertainty shocks. Fifth, the economic impact of past uncertainty news on stock returns is found to be contemporaneously relatively strong. However, it becomes significantly less severe beyond one month.

The empirical findings are generally at stark odds with conventional theories of the informational disadvantage of foreign investors in the host market. These theories characterize foreign investors as uninformed traders based on the findings of positive feedback trading in the early studies. In contrast, the findings of the current study suggest that foreign investors in the South Korean equity market do not naively trend-chase or follow such a trading behavior due to informational disadvantage. Hence, the assumption that foreign investors lack local information is rejected outright. Furthermore, the results provide limited support to Hau and Rey's (2004) portfolio rebalancing model.

\section{Appendix A}

\section{The MCMC simulations}

The time-varying coefficients of the TVP-VAR model are formulated to follow the firstorder random walk process. This process can be estimated using the MCMC method in the context of the Bayesian inference which involves specifying a prior density to construct a posterior distribution. The priors should be carefully chosen because the state variables of the TVP-VAR model are modeled as a random walk. However, we can select a flat uninformative prior for the initial state of the time-varying coefficients as discussed in Koop and Korobilis (2010). The MCMC algorithm, then, proceeds by recursively sampling the conditional posterior distribution where the most recent values of the conditioning parameters are used in the simulation. As already mentioned, the recursive sampling of the VAR system is based on a lower triangular matrix. In this study, the priors described below are assumed for the $i$ th diagonals of the covariance matrices for the TVP-VAR-SV models.

$$
\left(\Sigma_{b}\right)_{i}^{-2} \sim \operatorname{Gamma}(40,0.2)\left(\Sigma_{a}\right)_{i}^{-2} \sim \operatorname{Gamma}(4,0.2)\left(\Sigma_{h}\right)_{i}^{-2} \sim \operatorname{Gamma}(4,0.2)
$$



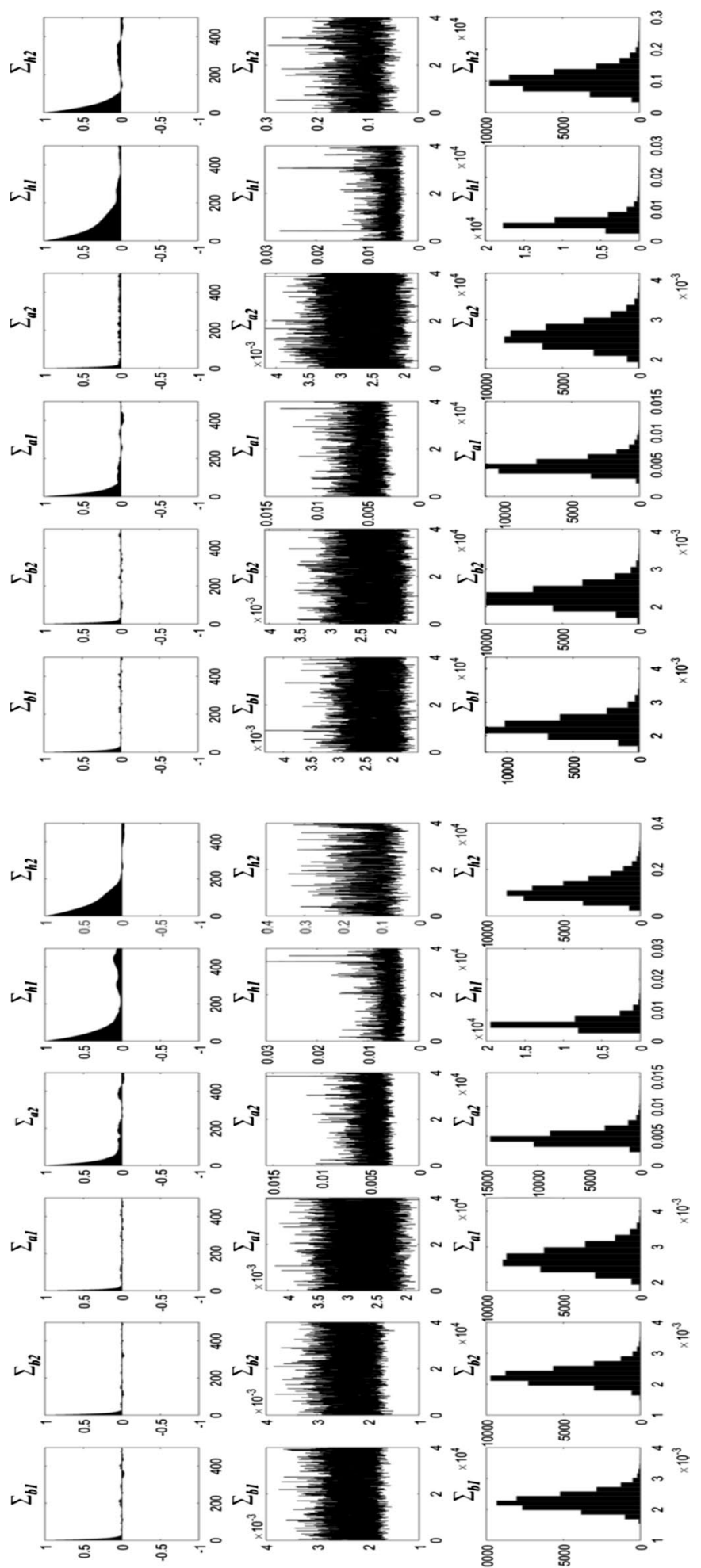

Fig. 9 MCMC samples of the TVP-VAR-SV parameters. Left: Parameters of TVP-VAR-SV with the ordering $\{E P U, N E F, R\}$. Right: Parameters of TVP-VAR-SV with the ordering $\{E P U, R, N E F\}$. Sample autocorrelations (top), sample paths (middle) and posterior histograms (bottom). The estimates of $\Sigma_{\beta}$ and $\Sigma_{a}$ are multiplied by 100 . The TVP-VAR-SV models are estimated using one lag 
Table 2 Estimation results of the TVP-VAR-SV parameters with the ordering $\{E P U, N E F, R\}$

\begin{tabular}{lllllll}
\hline Parameters & Mean & St.Dev & $\mathbf{9 5 \%} \mathbf{U}$ & $\mathbf{9 5 \%} \mathbf{L}$ & $\mathbf{C D}$ & Inef \\
\hline$\left(\Sigma_{\beta}\right)_{1}$ & 0.0023 & 0.0003 & 0.0018 & 0.0028 & 0.083 & 14.65 \\
$\left(\Sigma_{\beta}\right)_{2}$ & 0.0023 & 0.0003 & 0.0018 & 0.0029 & 0.069 & 12.78 \\
$\left(\Sigma_{a}\right)_{1}$ & 0.0027 & 0.0003 & 0.0022 & 0.0033 & 0.637 & 13.45 \\
$\left(\Sigma_{a}\right)_{2}$ & 0.0047 & 0.0011 & 0.0032 & 0.0073 & 0.635 & 53.5 \\
$\left(\Sigma_{h}\right)_{1}$ & 0.0058 & 0.002 & 0.0034 & 0.0104 & 0.445 & 94.24 \\
$\left(\Sigma_{h}\right)_{2}$ & 0.1136 & 0.0431 & 0.0478 & 0.2138 & 0.468 & 120.77 \\
\hline
\end{tabular}

Table 3 Estimation results of the TVP-VAR-SV parameters with the ordering $\{E P U, R, N E F\}$

\begin{tabular}{lllllll}
\hline Parameters & Mean & SD & $\mathbf{9 5 \%} \mathbf{U}$ & $\mathbf{9 5 \%} \mathbf{L}$ & $\mathbf{C D}$ & Inef \\
\hline$\left(\Sigma_{\beta}\right)_{1}$ & 0.0023 & 0.0003 & 0.0018 & 0.0029 & 0.5 & 14.89 \\
$\left(\Sigma_{\beta}\right)_{2}$ & 0.0023 & 0.0003 & 0.0018 & 0.0029 & 0.006 & 12.03 \\
$\left(\Sigma_{a}\right)_{1}$ & 0.0049 & 0.0011 & 0.0032 & 0.0077 & 0.232 & 50.84 \\
$\left(\Sigma_{a}\right)_{2}$ & 0.0026 & 0.0003 & 0.0021 & 0.0033 & 0.936 & 18.41 \\
$\left(\Sigma_{h}\right)_{1}$ & 0.006 & 0.0022 & 0.0035 & 0.0114 & 0.000 & 125.33 \\
$\left(\Sigma_{h}\right)_{2}$ & 0.1035 & 0.0299 & 0.0544 & 0.1712 & 0.77 & 71.56 \\
\hline
\end{tabular}

The flat priors set for the initial state of the time-varying coefficients are as follows: $\mu_{\beta_{0}}=\mu_{a_{0}}=\mu_{h_{0}}=0$ and $\Sigma_{\beta_{0}}=\Sigma_{a_{0}}=\Sigma_{h_{0}}=10 \times I$. Using the MCMC algorithm, we draw $M=40,000$ samples after discarding the initial 4000 samples.

Figure 9 shows the sample of the autocorrelation function, the sample paths, and the posterior histograms for the selected parameters estimated by TVP-VAR-SV with the alternative orders discussed earlier. The autocorrelation sample shows a steep decrease in the autocorrelations of the samples drawn by the MCMC algorithm. The sample paths in the middle are stable indicating that MCMC sampling has efficiently produced most of the samples with low autocorrelations. Therefore, the sequence of the MCMC sampling is stationary and it converges in distribution to normal standards as shown in the bottom row.

The parameter estimations of the TVP-VAR-SV models are presented in Tables 2 and 3 , respectively. These tables contain the estimates for posterior means, standard deviations, the 95\% credible intervals, the convergence diagnostics (CD) of Geweke (1992), and the inefficiency factors, which are computed using the MCMC samples. Based on the CD statistics, the null hypothesis of the convergences to posteriors distribution is not rejected at $5 \%$ for most of the parameters of both TVP-VAR models. Meanwhile, the inefficiency factors are quite low, meaning that the number of efficient samples is highly sufficient for inference. The posterior means of the parameters also fall within the $95 \%$ credible intervals. 


\section{Appendix B}

See Figs. 10 and 11.

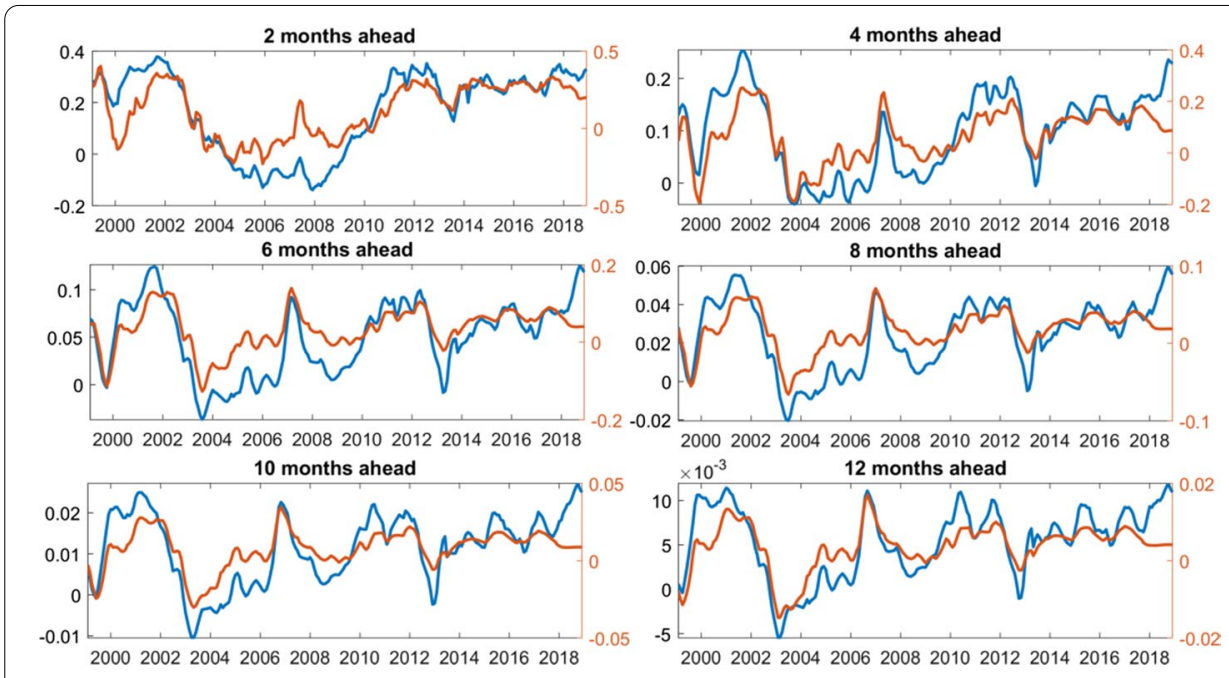

Fig. 10 Estimations of stock return responses to uncertainty under alternating orders. Right axis: Estimations under the order $\{E P U, R, N E F\}$. Left axis: Estimations under the order $\{E P U, N E F, R\}$

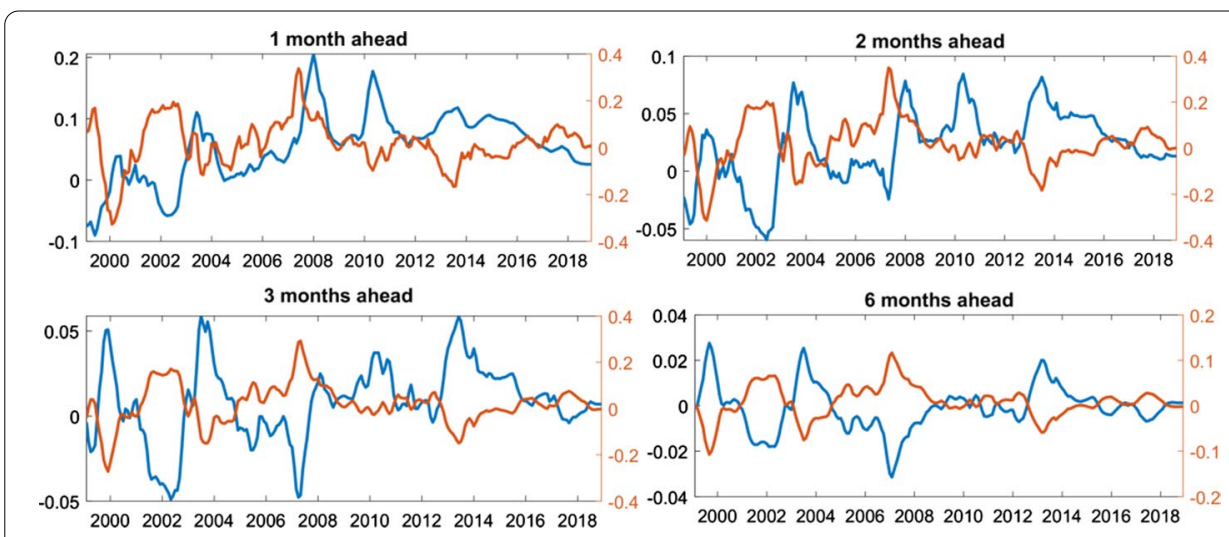

Fig. 11 Foreigners' feedback trading and net flow response to uncertainty shocks. Left axis: Response of net flows to stock return shocks (blue). Right axis: Response of net flows to uncertainty shocks (orange)

\section{Abbreviations}

EPU: Economic uncertainty index; ICSS: Iterated cumulative sum of squares; MCMC: Markov chain Monte Carlo; NEF: Net foreign equity flows; R: Stock returns; TVP-VAR-SV: Time-varying parameters vector autoregressive with stochastic volatility.

\section{Acknowledgements}

We sincerely thank the anonymous reviewers for their insightful comments.

\section{Authors' contributions}

The authors equally contributed to the writing and analysis of the paper, data and empirical results were acquired by the corresponding author. All authors read and approved the final manuscript. 


\section{Funding}

This research has not been supported or funded by any organization.

Availability of data and materials

The data that support the findings of this study are available from the corresponding author upon reasonable request.

\section{Declaration}

\section{Competing interests}

The authors declare that they have no competing interests.

\section{Author details}

${ }^{1}$ Graduate School of Social Sciences, Anadolu University, Eskişehir, Tepebaşı 26470, Turkey. ${ }^{2}$ Open Education Faculty, Anadolu University, Eskişehir, Tepebaşı 26470, Turkey.

Received: 9 August 2020 Accepted: 18 June 2021

Published online: 28 June 2021

\section{References}

Ahmad W, Sehgal S (2015) Regime shifts and volatility in BRIICKS stock markets: an asset allocation perspective. Int J Emerg Mark 10(3):383-408

Albuquerque R, Bauer GH, Schneider M (2009) Global private information in international equity markets. J Financ Econ 94(1):18-46

Antonakakis N, Chatziantoniou I, Filis G (2013) Dynamic co-movements of stock market returns, implied volatility and policy uncertainty. Econ Lett 120(1):87-92

Arouri M, Estay C, Rault C, Roubaud D (2016) Economic policy uncertainty and stock markets: long-run evidence from the US. Financ Res Lett 18:136-141

Bae SC, Min JH, Jung S (2011) Trading behavior, performance, and stock preference of foreigners, local institutions, and individual investors: evidence from the Korean stock market. Asia-Pac J Financ Statem 40:199-239

Baker SR, Bloom N, Davis SJ (2016) Measuring economic policy uncertainty. Quarterly J Eco 131(4):1593-1636

Bekaert G, Harvey CR (1997) Emerging equity market volatility. J Financ Econ 43(1):29-77

Bekaert G, Harvey CR (2000) Foreign speculators and emerging equity markets. J Finance 55(2):565-613

Bekaert G, Erb CB, Harvey CR, Viskanta TE (1997) What matters for emerging equity investments. Emerg Mark Q 1:17-46

Bekaert G, Erb CB, Harvey CR, Viskanta TE (1998) Distributional characteristics of emerging markets returns and asset allocation. J Portfolio Man 24(2):102-116

Bekaert G, Harvey CR, Lumsdaine RL (2002) The dynamics of emerging market equity flows. J Intern Mon Fin 21(3):295-350

Bohn H, Tesar LL (1996) U.S. equity investment in foreign markets: portfolio rebalancing or return chasing. Am Econ Rev 86(2):77-81

Brennan MJ, Cao HH (1997) International portfolio investment flows. J Finance 52(5):1851-1880

Brennan MJ, Cao HH, Strong N, Xu X (2005) The dynamics of international equity market expectations. J Fin Eco 77(2):257-288

Brown RL, Durbin J, Evans JM (1975) Techniques for testing the constancy of regression relationships over time. J R Stat Soc 37(2):149-192

Canh PN, Binh NT, Thanh SD, Schinckus C (2020) Determinants of foreign direct investment inflows: the role of economic policy uncertainty. Int Econ 161:159-172

Chai-Anant C (2003) Friends or foes? Foreign investors in Thai stock market during 1994-1998. Bank of Thailand Working Paper No 2003-08

Chai-Anant C, Ho C (2008) Understanding Asian equity flows, market returns and exchange rates. BIS Working Paper No. 245

Chan LK, Lakonishok J (1995) The behavior of stock prices around institutional trades. J Finance 50(4):1147-1174

Choe H, Kho B, Stulz RM (1999) Do foreign investors destabilize stock markets? The Korean experience in 1997. J Financ Econ 54(2):227-264

Choe H, Kho B, Stulz RM (2005) Do foreign investors have an edge? The trading experience of foreign investors in Korea. Rev Financ Statem 3:795-829

Choi S, Fuceri D, Yoon C (2020) Policy uncertainty and foreign direct investment. Rev Int Econ (Forthcoming)

Clark J, Berko E (1997) Foreign investment fluctuations and emerging market stock return: the case of Mexico. New York: Federal Reserve Bank of New York Staff Report No. 24

Dahlquist M, Robertsson G (2004) A note on foreigners'trading and price effects across firms. J Bank Finance 28(3):615-632

de Jong P, Neil S (1995) The simulation smoother for time series models. Biometrika 82(2):339-350

DeSantis G, Imrohoroğlu S (1997) Stock returns and volatility in emerging financial markets. J Int Money Finance 16(4):561-579

Durbin J, Koopman SJ (2002) A simple and efficient simulation smoother for state space time series analysis. Biometrika 89(3):603-615

Faruk B, Uddin GS, Mudassar H, Yoon S (2017) Cross-country determinants of economic policy uncertainty spillovers. Eco Let 156:179-183

Froot KA, Ramadorai T (2008) Institutional portfolio flows and international investments. Rev Financ Stud 21(2):937-971

Froot KA, O'Connell PG, Seasholes MS (2001) The portfolio flows of international investors. J Financ Econ 59(2):151-193 
Gilchrist S, Sim J, Zakrajsek E (2014) Uncertainty, financial frictions, and investment dynamics. NBER Working Paper No. w20038.

Griffin JM, Nardari F, Stulz RM (2004) Are daily cross-border equity flows pushed or pulled? Rev Econ Statem 86(3):641-657

Grinblatt M, Keloharju M (2000) The investment behavior and performance of various investor types: a study of Finland's unique dataset. J Financ Econ 55(1):43-67

Gulen H, lon M (2016) Policy uncertainty and corporate investment. Rev Financ Statem 29(3):523-564

Harvey CR, Travers KE, Costa MJ (2000) Forecasting emerging market returns using neural networks. Emerg Mark Q 4:43-54

Hasbrouck J (1991) Measuring the information content of stock trades. J Finance 46(1):179-207

Hau H, Rey H (2004) Can portfolio rebalancing explain the dynamics of equity returns, equity flows, and exchange rates? Am Econ Rev 94(2):126-133

Hong G, Lee BS (2011) The trading behavior and price impact of foreign, institutional, individual investors and government: evidence from Korean equity market. Jpn World Econ 23(4):273-287

Inclan C, Tiao GC (1994) Use of cumulative sums of squares for retrospective detection of changes of variance. J Am Stat Assoc 89(427):913-923

Jeon JQ, Moffet CM (2010) Herding by foreign investors and emerging market equity returns: evidence from Korea. Int Rev Econ Finance 19(4):698-710

Karolyi AG (2002) Did the Asian financial crisis scare foreign investors out of Japan. Pacific-Basin Financ J 10(4):411-442

Kawakatsu H, Morey MR (2014) An empirical examination of financial liberalization and the efficiency of emerging market stock prices. J Financ Res 22(4):385-411

Keim DB, Madhavan A (1996) The upstairs market for large-block transactions: Analysis and measurement of price effects. The Rev of Fin Stud 9(1):1-36

Kim Y, Jo G (2019) The impact of foreign investors on the stock price of Korean enterprises during the global financial crisis. Sustainability 11(6)

Kim HE, Singal V (2000) Stock market openings: experience of emerging economies. J Bus 73(1):25-66

Koop G, Korobilis D (2010) Bayesian multivariate time series methods for empirical macroeconomics. Fou Tren Econom $3(4): 267-358$

Kumar M (2010) A time-varying parameter vector autoregression model for forecasting emerging market exchange rates. Int J Econ Appl Res 3(2):21-39

Lai H, Wang K (2014) Relationship between the trading behavior of three institutional investors and Taiwan Stock Index futures returns. Econ Model 41:156-165

Liew P, Lim K, Goh K (2018) Foreign equity flows: Boon or bane to the liquidity of Malaysian stock market? N Am J Econ Financ 45:161-181

Liu L, Zhang T (2015) Economic policy uncertainty and stock market volatility. Fin Res Lett 15:99-105

Maharaj EA, Galagedera DU, Dark J (2011) A comparison of developed and emerging equity market return volatility at different time scales. Manag Fin 37(10):940-952

Nakajima J (2011) Time-varying parameter VAR model with stochastic volatility: an overview of methodology. Monet Econ Stud 29:107-142

Nakajima J, Kasuya M, Watanabe T (2011) Bayesian analysis of time-varying parameter vector autoregressive model for the Japanese economy and monetary policy. J Jpn Int Econ 25(3):225-245

Pagliari MS, Hannan, SA (2017) The volatility of capital flows in Emerging markets: measures and Determinants. IMF Working Papers $17 / 41$

Pastor L, Veronesi P (2013) Political uncertainty and risk premia. J Financ Econ 110(3):520-545

Porras E, Ülkü N (2015) Foreigners'trading and stock returns in Spain. J Int Financ Mark Inst Mon 34:111-126

Primiceri GE (2005) Time varying structural vector autoregressions and monetary policy. Rev Econ Stud 72(3):821-852

Richards A (2005) Big fish in small ponds: the trading behavior and price impact of foreign investors in Asian emerging equity markets. J Financ Quant Anal 40(1):1-27

Rivoli P, Salorio E (1996) Foreign direct investment and investment under uncertainty. J Int Bus Statem 27:335-357

Samarkoon LP (2009) The relation between trades of domestic and foreign investors and stock returns in Sri Lanka. J Int Financ Mark Inst Mon 19(5):850-861

Schaller H, Van Norden S (1997) Regime switching in stock market returns. App Fin Econ 7(2):177-191

Sims CA, Zha T (2006) Does monetary policy generate recessions? Macro Dyn 10(2):231-272

Tayde N, Rao N (2011) Do foreign institutional investors (Flls) exhibit herding and positive feedback trading in Indian Stock Markets? In: Boubakri N, Cosset JC (eds) Institutional investors in global capital markets. Emerald Group Publishing Limited, Bingley, pp 169-185

Tesar LL, Werner IM (1995a) Home bias and high turnover. J Int Mon Finance 14(4):467-492

Tesar LL, Werner IM (1995b) US equity investment in emerging stock markets. World Bank Econ Rev 9(1):109-129

Ülkü N (2015) The interaction between foreigners'trading and stock market returns in emerging Europe. J Emp Finance 33:243-262

Ülkü N, Ikizlerli D (2012) The interaction between foreigners' trading and emerging stock returns: evidence from Turkey. Emerg Mark Rev 13(3):381-409

Ülkü N, Karpova Y (2014) Do international equity investors rebalance to manage currency exposure? A study of Greece investor flows data. J Int Financ Mark Inst Mon 29:150-169

Ülkü N, Weber E (2014) Identifying the interaction between foreign investor flows and emerging stock market returns. Rev of Fin 18(4):1541-1581

Watanabe T, Omori Y (2004) A multi-move sampler for estimating non-Gaussian time series models: comments on Shephard \& Pitt (1997). Biometrika 91(1):246-248

Wen F, Xu L, Ouyang G, Kou G (2019) Retail investor attention and stock price crash risk: evidence from China. Int Rev Financ Anal 65:101376 


\section{Publisher's Note}

Springer Nature remains neutral with regard to jurisdictional claims in published maps and institutional affiliations.

Submit your manuscript to a SpringerOpen ${ }^{\circ}$ journal and benefit from:

- Convenient online submission

- Rigorous peer review

- Open access: articles freely available online

- High visibility within the field

- Retaining the copyright to your article

Submit your next manuscript at $\gg$ springeropen.com 